\title{
Information Storage and Retrieval
}

National Cancer Institute

\section{Source}

National Cancer Institute. Information Storage and Retrieval. NCI Thesaurus. Code C16734.

Research regarding the systematic process of collecting and cataloging data so that they can be located and displayed on request. 